\title{
Respiratory effects of occupational exposures in a milk powder factory
}

\author{
P. Sripaiboonkij*, W. Phanprasit ${ }^{\#}$ and M.S. Jaakkola*,
}

\begin{abstract}
Ingestion of milk powder is a known cause of allergies in children, but the risks to respiratory health from exposure to inhaled milk powder have not been studied previously. The aim of the present study was to assess the effects of occupational exposures in a milk powder factory on respiratory symptoms and lung function.
\end{abstract}

A cross-sectional study was conducted on 167 milk powder factory workers (response rate $\mathbf{7 7 \%}$ ) and 76 office workers (73\%) from four factories in Thailand. All participants answered a questionnaire and performed spirometry. Measurements of concentrations of dust were used to give additional information on exposures.

Mean respirable dust concentrations in the factory were $0.02-2.18 \mathrm{mg} \cdot \mathrm{m}^{-3}$. The risk of breathlessness and nasal symptoms were significantly increased in production and packing staff. The risk of skin symptoms was significantly increased in those adding vitamin mixture to milk powder. Factory workers showed significantly lower forced expiratory volume in one second measured as percentage of predicted value.

The present study provides new evidence that workers exposed to milk powder by inhalation are at an increased risk of nasal symptoms, wheezing and breathlessness, and exhibit reduced spirometric lung function, even at relatively low air concentrations of milk dust.

\section{KEYWORDS: Lung function, milk powder, natural rubber latex, respiratory symptoms}

ngestion of cow's milk is a known cause of allergies, especially in children [1-3], but the potential risks to respiratory health of inhalation of milk powder have not been studied previously. In order to address this question, workers at a factory in Thailand producing cow's milk powder were studied. The milk powder is used as nutrition for babies and children after mixing it with water. Since exposure control procedures are generally strict in food processing industries [4, 5], any respiratory effects seen in this population might be of relevance to other occupational groups that can be exposed to milk powder under less controlled conditions, such as nurses in paediatric care, nannies and bakers.

The milk powder factory comprised several departments that were located in different areas and separated from each other by walls, including the office, production area, vitamin addition area, quality control area and packing area. The factory generally placed emphasis on good hygiene conditions and had installed local extractors and enclosed some of the processes. The processes in the factory are presented in figure 1 .

The objective of the present study was to assess the relationship of occupational exposures in milk powder factory workers to respiratory symptoms and spirometric lung function.

\section{METHODS}

\section{Study design}

A cross-sectional study was performed among all workers in a milk powder factory and among office workers from a total of four factories in Thailand between September 2006 and January 2007. All participants answered an intervieweradministered questionnaire and performed spirometry. The study was approved by the ethics committee of Mahidol University, Bangkok, Thailand. All participants signed their informed consent before participation.

\section{Study population}

Of a total of 245 workers in the milk powder factory, 167 (response rate 77\%) participated in the present study. These included 130 production and packing workers, 22 workers adding vitamin mixture and 15 quality control staff members. Altogether 76 office workers (response rate $73 \%$ ) from four factories formed the unexposed reference population, including 24 office workers from the milk powder factory, 18 from a microfibre factory, 18 from a wood furniture factory and 16 from a tile factory. Office workers were managers, other administrative staff, chauffeurs and security staff checking identification badges at the gate.

\section{AFFILIATIONS}

${ }^{*}$ Institute of Occupational and Environmental Medicine, University of Birmingham, Birmingham, UK. ${ }^{*}$ Dept of Occupational Health and Safety, Faculty of Public Health, Mahidol University, Bangkok, Thailand.

'Respiratory Medicine Section, Division of Medicine, University of Oulu, Oulu, Finland

\section{CORRESPONDENCE}

M.S. Jaakkola Institute of Occupational and Environmental Medicine University of Birmingham Edgbaston Birmingham B15 2TT UK

Fax: 441214146217

E-mail: m.jaakkola@bham.ac.uk

Received:

August 142007

Accepted after revision:

November 042007

\section{SUPPORT STATEMENT}

The present study was supported by a grant from the Royal Thai Government (Bangkok, Thailand).

STATEMENT OF INTEREST A statement of interest for W. Phanprasit can be found at www.erj.ersjournals.com/misc/ statements.shtml 


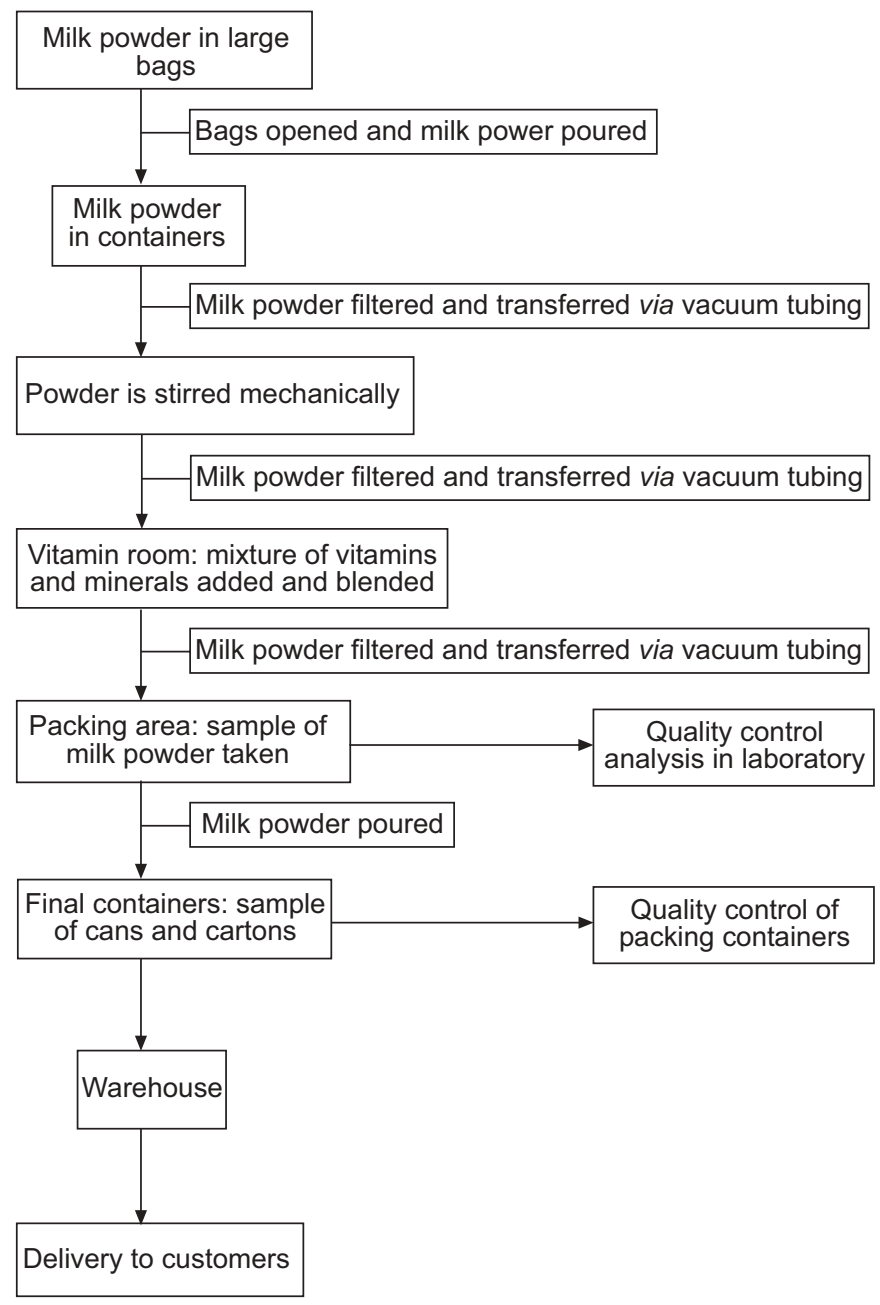

FIGURE 1. Processes taking place in the milk powder factory.

\section{Measurement methods}

Questionnaire

A questionnaire on respiratory health, occupational exposures and lifestyle factors was modified from the Finnish Environment and Asthma Study [6-13]. The questionnaire enquired about job history and specific exposures in current and previous jobs. The questionnaire was translated into Thai and then translated back into English in order to ensure the validity of the translation.

\section{Spirometry}

Participants performed spirometry according to the standards of the American Thoracic Society [14] using a Minato Autospiro PAL spirometer (Minato Medical Sciences, Osaka, Japan). The best forced expiratory volume in one second (FEV1) and forced vital capacity (FVC) out of a minimum of three acceptable forced expirations were used as outcomes. Predicted values from a Thai population [15] were used to calculate FEV1 and FVC as a percentage of the predicted value.

\section{Outcome assessment}

The outcomes of interest included the occurrence of respiratory symptoms within the past 12 months, and asthma ever and within the past 12 months, based on questionnaire information. These were defined as: 1) cough: recurrent or prolonged cough; 2) phlegm production: recurrent or prolonged phlegm production; 3) wheezing: wheezing or whistling of the chest; 4) breathlessness: chest tightness or difficulty breathing; 5) nasal symptoms: dryness, itching or smarting of nose, stuffy nose, runny nose or repeated sneezing; 6) eye symptoms: dryness of eyes, itchy eyes, irritation or smarting of eyes, watering of eyes or redness of eyes; 7) skin symptoms: dryness or flaking of skin, itchy skin, irritation, smarting or redness of skin, sore or tender skin, or urticaria; 8) current asthma: asthma diagnosed by a physician within the previous 12 months; 9) asthma ever: asthma diagnosed by a physician ever during lifetime. Lung function outcomes included FEV1 and FVC (absolute values and percentage of predicted) based on the best values of FEV1 and FVC obtained on spirometry.

\section{Exposure assessment}

Occupational exposures in the milk powder factory were the exposures of interest. First, exposure was assessed based on whether the subject was a factory (coded 1) or office worker (coded 0). Secondly, exposure among factory workers was assessed based on their job tasks and location of work area, classified into three groups: production line and packing staff, staff adding vitamins, and quality control staff. Production line staff were exposed to milk powder. Staff adding vitamin mixture and packing staff were also exposed to a mixture of vitamins, minerals and corn syrup. In addition, vitamin-adding staff and quality control staff were exposed to natural rubber latex (NRL). Staff responsible for quality control of the milk powder were exposed to many other chemicals. Indicator variables were formed for the three job categories (coded 1 if the participant belonged to the job category in question; 0 if not), whereas the office workers formed the common reference category. Thirdly, exposure was assessed based on reported exposure to specific substances given in a list in the questionnaire. The most commonly reported specific exposures were milk (60\%) and NRL (27\%). Quality control staff reported exposure to several chemicals, including sulphuric acid $(0.6 \%)$, ethanol $(6.6 \%)$, methanol $(1.2 \%)$, sodium hydroxide $(3.6 \%)$ and ammonium hydroxide $(1.8 \%)$. Since numbers were low for these specific exposures, only exposure to milk (yes $=1 ;$ no $=0$ ) and NRL (yes $=1 ;$ no=0) were investigated separately, adjusted for each other in regression models. In addition, the specific exposures were categorised into sensitisers and irritants. Sensitisers included milk powder, welding fumes, cutting oils, NRL, tetrahydrofuran and glues. Irritants included sulphuric acid, urea, sodium hydroxide, ammonium hydroxide, ethyl acetate, ethanol, methanol, nitric acid, glacial acetic acid, acetone, thinner, microfibres, solvents, paints, acetonitrile and hexane.

Additional information on exposures was provided by annual measurements of dust and chemicals in the air of the factory, performed by an independent consulting company (W. Phanprasit is a member of the monitoring team). Results from these were available for the previous 3 yrs (2003-2005). Respirable dust concentrations were measured using the method of the US National Institute for Occupational Safety and Health (method number 0600) [16].

\section{Data analysis}

Odds ratios (ORs) and 95\% confidence intervals (CIs) were calculated to quantify the relationship between exposure and 
TABLE 1 Occurrence of respiratory symptoms and asthma in the study population by worker type

\begin{tabular}{|c|c|c|c|c|}
\hline & \multirow[t]{2}{*}{ Office workers } & \multicolumn{3}{|c|}{ Factory workers } \\
\hline & & Total & Production and packing & Vitamin-adding \\
\hline Subjects n & 76 & 167 & 130 & 22 \\
\hline Prolonged cough & $13(17.1)$ & $31(18.6)$ & 25 (19.2) & $6(27.3)$ \\
\hline Phlegm production & $24(31.6)$ & $69(41.3)$ & $55(42.3)$ & $9(40.9)$ \\
\hline Nasal symptoms & $21(27.6)$ & $59(35.3)$ & $47(36.2)$ & $9(40.9)$ \\
\hline Eye symptoms & $23(30.3)$ & 55 (32.9) & 38 (29.2) & $9(40.9)$ \\
\hline Skin symptoms & $23(30.3)$ & $42(25.1)$ & 29 (22.3) & $10(45.5)$ \\
\hline Asthma ever & $3(3.9)$ & $5(3.0)$ & $5(3.8)$ & $0(0)$ \\
\hline Current asthma & $0(0)$ & $2(1.2)$ & $2(1.5)$ & $0(0)$ \\
\hline
\end{tabular}

Data are presented as $n(\%)$, unless otherwise indicated.

outcome. A model was fitted for each respiratory symptom and asthma separately. Three types of exposure variables, described in the Exposure assessment section, were fitted in different sets of models. All models were adjusted for potential confounders, including sex, age ( $\leqslant 25 \mathrm{yrs}, 26-30 \mathrm{yrs}$ or $\geqslant 31 \mathrm{yrs})$, educational level (primary/high school, vocational school/college or bachelor/higher university degree), parental atopy or asthma (yes or no), smoking status (current, ex- or never-smoker), exposure to second-hand smoke (SHS) at home and/or at work (yes or no) and work stress (a lot/very much stress or some/a little/no stress), on multivariate logistic regression.

Multiple linear regression was used to analyse the effect of exposures on lung function. A separate model was fitted for each outcome, including FEV1, FVC, FEV1 \% pred and FVC \% pred. Models of lung function levels were adjusted for sex, age, height, educational level, smoking status, SHS exposure at home and/or at work, and parental atopy/asthma. FEV1 \% pred and FVC \% pred were already controlled for sex, age and height in the prediction equations.

\section{RESULTS}

\section{Characteristics and symptoms of the study population}

The study population included 142 males and 101 females aged $18-60$ yrs. Factory workers were more often male, younger, of lower educational level and current smokers than the office workers (Appendix 1). The multivariate analyses adjusted for all of these variables, as well as others shown in Appendix 1.

Table 1 shows the occurrence of respiratory symptoms by work task in the factory or being an office worker. The number of quality control staff was so small $(n=15)$ that they were excluded as a specific task group from the analyses. Factory workers experienced twice as much wheezing and breathlessness (24 and $33 \%$, respectively) as office workers (12 and $16 \%$, respectively). Staff adding vitamins to milk powder showed a high occurrence of eye $(41 \%)$ and skin symptoms $(46 \%)$.

\section{Air measurements}

Air concentrations of respirable dust, consisting mainly of milk powder, had been monitored in the factory by an independent

TABLE 2 Crude and adjusted odds ratio (OR) of respiratory symptoms and asthma in relation to factory work and adjusted OR by job task ${ }^{\#}$

\begin{tabular}{|c|c|c|c|c|}
\hline & \multicolumn{2}{|c|}{ Total } & \multirow[t]{2}{*}{ Production and packing } & \multirow[t]{2}{*}{ Vitamin-adding" } \\
\hline & Crude & Adjusted" & & \\
\hline Subjects $n$ & \multicolumn{2}{|c|}{167} & 130 & 22 \\
\hline Prolonged cough & $1.11(0.54-2.25)$ & $0.82(0.31-2.17)$ & $0.86(0.32-2.34)$ & $1.24(0.33-4.64)$ \\
\hline Phlegm production & $1.47(0.83-2.61)$ & $0.95(0.46-1.98)$ & $1.04(0.48-2.24)$ & $1.02(0.34-3.06)$ \\
\hline Nasal symptoms & $1.42(0.78-2.57)$ & $2.30(1.00-5.29)$ & $2.57(1.06-6.22)$ & $3.25(0.99-10.71)$ \\
\hline Eye symptoms & $1.14(0.64-2.05)$ & $1.63(0.74-3.59)$ & $1.43(0.61-3.33)$ & $1.89(0.59-6.13)$ \\
\hline Skin symptoms & $0.76(0.42-1.39)$ & $1.39(0.63-3.05)$ & $1.40(0.59-3.32)$ & $4.48(1.36-14.75)$ \\
\hline Asthma ever & $0.75(0.18-3.23)$ & $2.26(0.30-17.29)$ & $10.38(0.66-162.83)$ & NE \\
\hline
\end{tabular}

Data are presented as OR (95\% confidence interval), unless otherwise indicated. NE: could not be estimated due to small numbers. ${ }^{*}$ : office workers formed the reference category $(\mathrm{OR}=1)$; $"$ : adjusted for sex, age, education, parental atopy or asthma, smoking, exposure to second-hand smoke at work and/or at home, and work stress. 


\begin{tabular}{|c|c|c|c|}
\hline \multirow[t]{2}{*}{ TABLE 3} & \multicolumn{3}{|c|}{$\begin{array}{l}\text { Effect }(\beta) \text { of factory work on lung function } \\
\text { compared to office work }{ }^{\#}\end{array}$} \\
\hline & Total & $\begin{array}{l}\text { Production and } \\
\text { packing }\end{array}$ & Vitamin-adding \\
\hline Subjects $\mathbf{n}$ & 167 & 130 & 22 \\
\hline FEV $1 L^{*}$ & $0.002(-0.12-0.13)$ & $0.03(-0.10-0.17)$ & $-0.03(-0.23-0.16)$ \\
\hline FVC L" & $0.01(-0.12-0.14)$ & $0.05(-0.08-0.19)$ & $-0.10(-0.30-0.10)$ \\
\hline FEV 1 \% pred $^{+}$ & $-4.23(-7.70--0.76)$ & $-3.71(-7.43-0.01)$ & $-5.64(-11.60-0.32)$ \\
\hline FVC $\%$ pred $^{+}$ & $-2.99(-6.07-0.07)$ & $-2.30(-5.54-0.93)$ & $-6.26(-11.45--1.07)$ \\
\hline
\end{tabular}

Data are presented as $\beta$ (95\% confidence interval), unless otherwise indicated. The predicted values were controlled for age and height, and were calculated separately for males and females. FEV 1 : forced expiratory volume in one second; FVC: forced vital capacity; \% pred: \% predicted. "\#: office workers formed the reference category; ": effect estimate adjusted for sex, age, height, education, parental atopy or asthma, smoking, and second-hand smoke (SHS) exposure at work and/or at home; + ${ }^{+}$effect estimate adjusted for education, parental atopy or asthma, smoking and SHS exposure at work and/or at home.

consulting company during the preceding 3 yrs (2003-2005; Appendix 2). The mean concentrations ranged $0.02-2.18 \mathrm{mg} \cdot \mathrm{m}^{-3}$. Packing areas showed the highest concentrations (up to $2.18 \mathrm{mg} \cdot \mathrm{m}^{-3}$ ) and, in 2005, levels were above the action level of $50 \%$ of the threshold limit value, which is $3 \mathrm{mg} \cdot \mathrm{m}^{-3}$ for respirable dust. Concentrations above the action level had been measured in some production areas, vitamin rooms and warehouse areas in 2004-2005. The concentrations of different chemicals in the quality control department were generally low (data not shown) and $<50 \%$ of the threshold limit value.

\section{Factory work and respiratory symptoms and asthma}

Table 2 shows the ORs of respiratory symptoms and asthma in factory workers compared with office workers. The crude ORs of wheezing (2.31 (95\% CI 1.06-5.05)) and breathlessness (2.58 (1.29-5.17)) were significantly increased in factory workers, and remained increased after adjustment for confounders (1.74 (0.67-4.54) and $2.20(0.92-5.28)$, respectively), although no more significant. The risk of nasal symptoms was significantly increased after adjustment for confounders (2.30 (1.00-5.29)). The risk of ever asthma was high in factory workers (OR 2.26) but, due to the small number of asthmatics in the study population, the CI was wide. There were no cases of current asthma among the office workers (forming the reference group), so the OR for asthma diagnosed within the previous year could not be calculated.

Table 2 also presents ORs comparing different job tasks within the factory with office work. Production and packing staff exhibited a significantly increased risk of breathlessness (OR 3.05 (95\% CI 1.21-7.69)) and nasal symptoms (2.57 (1.06-6.22)). They also showed increased risk of ever asthma (OR 10.38) but, again, due to the small number of asthmatics, the CI was wide. Vitamin-adding staff showed a significantly increased risk of skin symptoms (4.48 (1.36-14.75)).

\section{Factory work and lung function}

As shown in table 3, factory workers had significantly lower FEV1 \% pred ( $\beta-4.23$ (95\% CI -7.70- -0.76)). No significant effects were detected on absolute FEV1 or FVC. This probably means that predicted values control better for age and height than adjusting for them in the regression model. Factory workers included more young males than office workers, which was reflected in higher mean lung function levels when not taking into account the predicted values. Vitamin-adding staff exhibited generally lower lung function, FVC \% pred being significantly reduced $(-6.26(-11.45--1.07))$.

\section{Specific exposures and respiratory effects}

Exposure to milk was related to a significantly increased risk of nasal symptoms (OR 2.35 (95\% CI 1.11-5.02)), and the risks of wheezing, eye symptoms and asthma were also increased (table 4). Exposure to NRL was related to an increased risk of skin symptoms (1.73 (0.70-4.30)) and breathlessness (1.73 (0.73$4.10)$ ), but the CIs were wide due to the small number of exposed subjects. When studying exposure to sensitisers, the ORs of phlegm production, wheezing, breathlessness, nasal symptoms, eye symptoms, skin symptoms and asthma were all increased in a consistent pattern, although only nasal symptoms

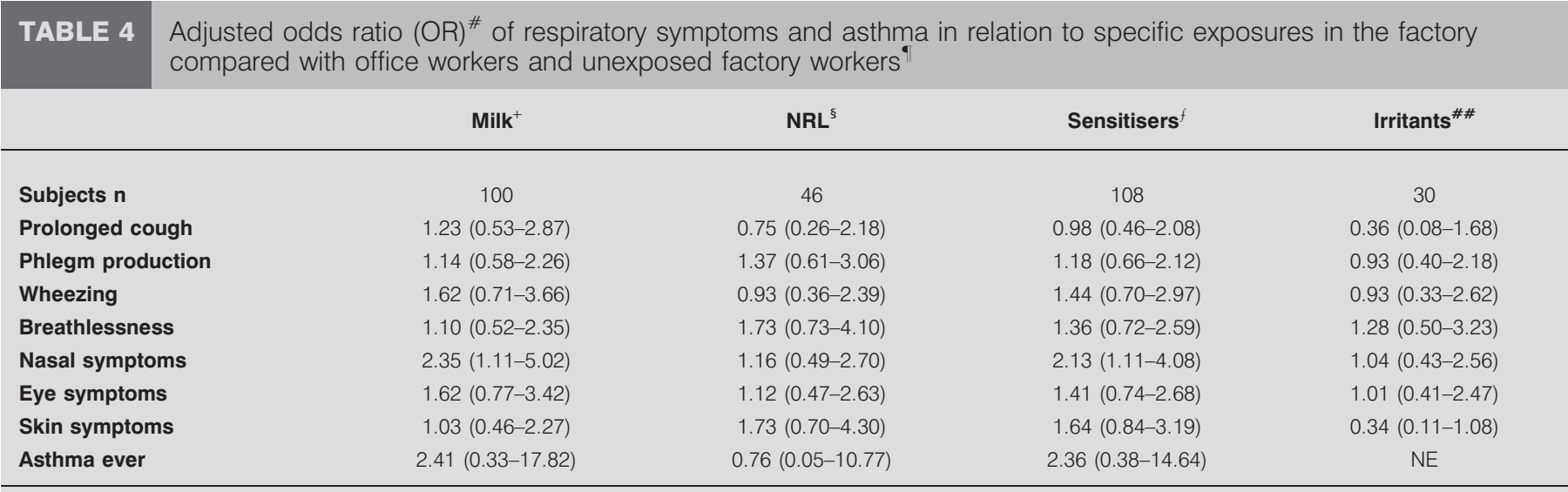

Data are presented as OR (95\% confidence interval), unless otherwise indicated. NRL: natural rubber latex; NE: could not be estimated due to small numbers. ${ }^{*}$ : adjusted for

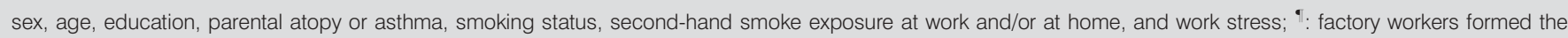

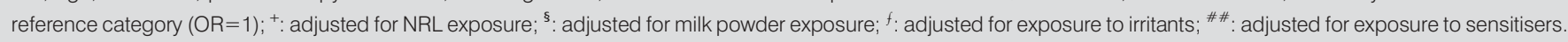




\begin{tabular}{|c|c|c|c|c|}
\hline \multirow[t]{2}{*}{ TABLE 5} & \multicolumn{4}{|c|}{$\begin{array}{l}\text { Effect }(\beta) \text { of specific exposures in the factory on lung function compared with office workers and unexposed factory } \\
\text { workers }\end{array}$} \\
\hline & Milk $^{\S}$ & $\mathbf{N R L}^{f}$ & Sensitisers ${ }^{\# \#}$ & Irritants \\
\hline Subjects $\mathrm{n}$ & 100 & 46 & 108 & 30 \\
\hline FEV $1 L^{\circ}$ & $-0.004(-0.16-0.07)$ & $0.11(-0.03-0.25)$ & $0.02(-0.08-0.12)$ & $-0.02(-0.17-0.13)$ \\
\hline FVC L & $-0.14(-0.26--0.01)$ & $0.20(0.05-0.35)$ & $-0.03(-0.14-0.07)$ & $0.04(-0.11-0.19)$ \\
\hline FVC $\%$ pred $^{+}$ & $-4.81(-8.13--1.50)$ & $4.04(-0.06-8.15)$ & $-2.96(-5.79--0.13)$ & $1.81(-2.48-6.09)$ \\
\hline
\end{tabular}

reached statistical significance (2.13 (1.11-4.08)). Exposure to irritants was not consistently related to respiratory symptoms.

Those exposed to milk showed lower spirometric lung function, the effect being significant for FVC ( $\beta-0.14$ (95\% CI -0.26- -0.01)) and FVC \% pred (-4.81 (-8.13- -1.50); table 5). Those with exposure to sensitisers exhibited generally lower lung function levels, the effect being significant for FVC \% pred $(-2.96(-5.79--0.13))$. No effect on lung function was seen in relation to exposure to irritants.

\section{DISCUSSION}

In the present study of exposure in a milk powder factory, factory workers were at increased risk of experiencing wheezing, breathlessness and nasal symptoms compared with office workers. They also showed increased risk of asthma (OR 2.26), but this was not statistically significant since only a few subjects in the population had been diagnosed with asthma. According to a PubMed database search, the present study is the first to investigate the risks related to inhalation of milk powder. Production and packing staff showed a significantly increased risk of breathlessness and nasal symptoms compared with office workers. Staff adding a vitamin mixture to milk powder showed a significantly increased risk of skin symptoms. Thus, factory workers experienced symptoms that are typically related to hypersensitivity of airways (i.e. wheezing, breathlessness and nasal symptoms) or skin, whereas they exhibited less irritant-type symptoms (i.e. cough or phlegm production). A hypersensitivity-type mechanism was also supported by the fact that the air concentrations of respirable dust (consisting mainly of milk powder) were generally rather low during the preceding 3-yr period, although there were some areas with concentrations above the action level in 2004 and 2005. Sensitising agents are known to be capable of inducing reactions even at low concentrations [17]. Milk powder contains milk proteins, including caseins, $\alpha$-lactalbumin and $\beta$-lactoglobulin, which are high molecular-weight compounds, typically inducing immunoglobulin (Ig)E-mediated hypersensitivity reactions. However, as specific IgE measurements were not performed in the present epidemiological study, the discussion regarding mechanisms remains speculative.

Exposure to sensitising agents showed a consistent pattern of increased risk of upper and lower respiratory symptoms, skin symptoms and asthma, whereas no such pattern was detected in relation to irritants. Milk was the most common specific exposure and seemed to be the major exposure underlying the respiratory symptoms and asthma. Exposure to NRL probably underlay the increased risk of skin symptoms, since the vitamin-adding staff used protective gloves, whereas the other job groups (apart from the quality control staff) did not, and did not show an excess of skin symptoms.

Lung function showed a pattern compatible with that of the respiratory symptoms. Factory workers exhibited significantly lower FEV1 \% pred compared with office workers. Lung function impairment was seen in relation to exposure to sensitisers, but irritants did not seem to affect lung function much. Among sensitisers, exposure to milk was related to a significantly reduced FVC and also lower FEV1.

The present results suggest that there is a need for surveillance of respiratory symptoms and spirometry in factories that have milk powder in the air, even if good exposure control measures are in effect, since significant adverse effects were detected at relatively low concentrations of milk powder. These results also raise the question as to whether other occupations with potential milk powder exposure, e.g. nurses in paediatric settings, nannies, bakers and other workers in food industries, should be investigated in relation to milk powder exposure by inhalation.

The present results on skin symptoms emphasise the point that food processing factories should be aware of the health risks related to NRL gloves and apply preventive measures. Based on experience from healthcare workers, effective preventive measures include use of low protein powder-free latex gloves or nonlatex gloves [18-21].

\section{Validity of results}

\section{Selection of the study population}

A good response rate (77\%) was achieved among milk powder factory workers and office workers $(73 \%)$, which reduced the likelihood of selection bias. Since the response rates for spirometry were even higher among both factory and office workers, it was possible to compare the lung function of respondents with that of the total population (Appendix 3). There were no significant differences in lung function, indicating that the participants were representative of the total population 
and there was no suggestion of any selection according to respiratory health status.

\section{Outcome and exposure assessment}

Outcome assessment was based on both symptom-reporting and objective lung function measurements, and gave consistent results. Factory exposures, mainly to milk powder, were related to asthma-type symptoms, i.e. wheezing and breathlessness, but only a small number of study subjects had been diagnosed with asthma. This may be because workers are afraid that they might lose their job if they have diagnosed asthma and thus do not seek medical help for their symptoms. Another potential explanation is that those with a diagnosed disease have left the workforce due to their disease. If the latter type of healthy worker selection were influencing the present risk estimates, it would result in underestimation of the true risks.

Exposure assessment was based on a combination of approaches. Job tasks and work areas were used to categorise the factory workers into different exposure groups, utilising knowledge of exposures in these different tasks and areas in combination with measurements of air concentrations of milk dust from the preceding 3 yrs. Exposure to some specific agents, categorised into sensitisers and irritants, was also investigated. Adverse effects of sensitisers on (objective) lung function in addition to (subjective) symptoms were detected, reducing the likelihood of biased reporting of exposures. Any nonsystematic error in exposure assessment would lead to underestimation of the true risks, as would a tendency to place symptomatic workers into low-exposure job tasks. Thus, some underestimation of the effect estimates is possible.

\section{Confounding}

Extensive data on potential confounders were collected in the questionnaire, and these factors were controlled for in the multivariate regression models in order to exclude them as potential explanations for the present findings. The most important differences between office and factory workers were that office workers included more females and older workers. As these characteristics are usually related to a higher prevalence of symptoms and lower lung function, any residual confounding would exert influence in the opposite direction to the present findings (which showed a significantly increased risk of symptoms and reduced lung function in the exposed factory workers), which provides further assurance that the present results are not explained by confounding. The prevalence of current smoking was somewhat higher among factory workers, and so adjustment was made for smoking habits. Office workers were somewhat heavier smokers than factory workers, meaning that any residual confounding by the amount of smoking would exert influence in the opposite direction to the present findings.

\section{Synthesis with previous knowledge}

In a PubMed database search, no previous study assessing the risk of adverse respiratory effects in relation to inhalation of milk powder was identified, but the present results are consistent with four case reports of occupational asthma [22], one arising from exposure to lactalbumin in a chocolate candy worker [23] and another from the same protein in a bakery worker [24], one from exposure to casein sprayed while tanning leather [25] and another from sodium caseinate exposure in a delicatessen factory worker [26]. These studies also reported three cases of occupational rhinitis caused by milk proteins $[23,25]$. The present finding of NRL exposure being related to skin symptoms is consistent with studies in healthcare workers [27] and dental workers [28, 29]. However, the present study seems to be the first to investigate the health risks of this exposure in food processing industries.

\section{CONCLUSION}

The present study provides new evidence that workers exposed to relatively low levels of milk powder by inhalation are at significantly increased risk of nasal symptoms, wheezing and breathlessness, and have reduced spirometric lung function. Workers exposed to a vitamin mixture added to milk also have an increased risk of skin symptoms, which is most probably related to their use of natural rubber latex gloves. The present study suggests that industrial workforces with milk powder exposure should undergo respiratory surveillance programmes, even if good exposure control measures are in effect. Other workforces with potential milk powder exposure by inhalation, e.g. nannies and bakers, should be investigated for potential health effects. Food processing industries should pay attention to preventive measures concerning use of natural rubber latex gloves.

\section{APPENDICES \\ Appendix 1}

\begin{tabular}{|c|c|c|c|}
\hline \multicolumn{4}{|c|}{$\begin{array}{l}\text { Characteristics of the total study population by } \\
\text { worker type }\end{array}$} \\
\hline & Office & Factory & Total \\
\hline Subjects $n$ & 76 & 167 & 243 \\
\hline \multicolumn{4}{|l|}{ Sex } \\
\hline Male & $35(46.1)$ & $107(64.1)$ & $142(58.4)$ \\
\hline Female & $41(53.9)$ & $60(35.9)$ & $101(41.6)$ \\
\hline \multicolumn{4}{|l|}{ Age yrs } \\
\hline$\leqslant 25$ & $9(11.8)$ & $96(57.5)$ & $105(43.2)$ \\
\hline $26-30$ & $15(19.7)$ & $48(28.7)$ & $63(25.9)$ \\
\hline$\geqslant 31$ & $52(68.4)$ & $23(13.8)$ & $75(30.9)$ \\
\hline \multicolumn{4}{|l|}{ Education } \\
\hline Primary/high school & $28(36.8)$ & $95(56.9)$ & $123(50.8)$ \\
\hline Vocational training/college & $17(22.4)$ & $33(19.8)$ & $50(20.7)$ \\
\hline Bachelor/higher university degree & $30(39.5)$ & $39(23.4)$ & $69(28.5)$ \\
\hline \multicolumn{4}{|l|}{ Smoking status } \\
\hline Never & $55(75.4)$ & $107(64.1)$ & $162(67.5)$ \\
\hline Past & $5(6.8)$ & $14(8.4)$ & $19(7.9)$ \\
\hline Current & $13(17.8)$ & $46(27.5)$ & $59(24.6)$ \\
\hline $\begin{array}{l}\text { SHS exposure at work and/or } \\
\text { home }\end{array}$ & $32(42.1)$ & $107(64.1)$ & $139(57.2)$ \\
\hline Parental atopy/asthma & $15(19.7)$ & $23(13.8)$ & $38(15.6)$ \\
\hline Work stress & $14(18.7)$ & $16(9.6)$ & $30(12.4)$ \\
\hline
\end{tabular}




\section{Appendix 2}

\begin{tabular}{lccc}
\multicolumn{4}{c}{$\begin{array}{c}\text { Air concentration of respirable dust by work area } \\
\text { during 2003-2005 }\end{array}$} \\
\cline { 2 - 4 } & \multicolumn{3}{c}{ Respirable dust $\mathbf{~ m g} \cdot \mathbf{m}^{-\mathbf{3}}$} \\
\cline { 2 - 4 } & $\mathbf{2 0 0 3}$ & $\mathbf{2 0 0 4}$ & $\mathbf{2 0 0 5}$ \\
\hline & & & \\
Production area & 1.60 & 1.34 & 0.13 \\
1 & 1.48 & 1.18 & $1.93^{1}$ \\
2 & & & \\
Vitamin-adding area & 0.61 & $1.93^{\#}$ & 1.60 \\
1 & 1.81 & 1.27 & 1.40 \\
2 & $\mathrm{NA}$ & $\mathrm{NA}$ & 1.49 \\
3 & & & \\
Packing area & 1.34 & 1.08 & 1.33 \\
1 & 1.17 & 1.06 & $2.14^{\#}$ \\
2 & 1.13 & 0.85 & $2.18^{\#}$ \\
3 & 1.33 & $1.65^{\#}$ & $\mathrm{NA}$ \\
4 & & & \\
Warehouse area & 1.67 & $1.71^{\#}$ & 1.42 \\
1 & $\mathrm{NA}$ & $\mathrm{NA}$ & 0.02 \\
\hline
\end{tabular}

Data are presented as mean. NA: not available. ${ }^{\#}$ : above the action level of $50 \%$ of the threshold limit value, which is $3 \mathrm{mg} \cdot \mathrm{m}^{-3}$.

\section{Appendix 3}

\begin{tabular}{|c|c|c|c|}
\hline & \multicolumn{3}{|c|}{$\begin{array}{l}\text { Lung function of questionnaire respondents } \\
\text { compared with the total population by worker } \\
\text { type }\end{array}$} \\
\hline & Respondents & All & p-value \\
\hline \multicolumn{4}{|l|}{ Office workers } \\
\hline Subjects n & 73 & 104 & \\
\hline FEV 1 L & $2.45 \pm 0.49$ & $2.49 \pm 0.55$ & 0.61 \\
\hline FVC L & $2.68 \pm 0.55$ & $2.71 \pm 0.63$ & 0.73 \\
\hline $\mathrm{FEV}_{1} \%$ pred & $87.69 \pm 11.72$ & $87.33 \pm 11.58$ & 0.83 \\
\hline FVC \% pred & $81.34 \pm 10.85$ & $80.58 \pm 10.76$ & 0.64 \\
\hline \multicolumn{4}{|c|}{ Factory workers } \\
\hline Subjects $n$ & 167 & 218 & \\
\hline $\mathrm{FEV}_{1} \mathrm{~L}$ & $2.67 \pm 0.57$ & $2.72 \pm 0.56$ & 0.40 \\
\hline FVC L & $2.87 \pm 0.63$ & $2.92 \pm 0.61$ & 0.44 \\
\hline FEV $1 \%$ pred & $83.86 \pm 12.09$ & $84.50 \pm 11.68$ & 0.60 \\
\hline FVC \% pred & $77.98 \pm 10.50$ & $78.35 \pm 10.27$ & 0.73 \\
\hline
\end{tabular}

Data are presented as mean $\pm S D$, unless otherwise stated. FEV1: forced expiratory volume in one second; FVC: forced vital capacity; \% pred: \% predicted.

\section{ACKNOWLEDGEMENTS}

The authors would like to thank C. Chaikittiporn (Mahidol University, Bangkok, Thailand) for supporting the data collection in Thailand and T. Sorahan (Institute of
Occupational and Environmental Medicine, University of Birmingham, Birmingham, UK) for guidance in using the SPSS statistical programme.

\section{REFERENCES}

1 Saarinen KM, Pelkonen AS, Mäkelä MJ, Savilahti E. Clinical course and prognosis of cow's milk allergy are dependent on milk specific IgE status. J Allergy Clin Immunol 2005; 116: 869-875.

2 Høst A. Frequency of cow's milk allergy in childhood. Ann Allergy Asthma Immunol 2002; 89: Suppl. 1, P33-P37.

3 Oranje AP, Wolkerstorfer A, de Waard-van der Spek FB. Natural course of cow's milk allergy in childhood atopic eczema/dermatitis syndrome. Ann Allergy Asthma Immunol 2002; 89: Suppl. 1, P52-P55.

4 Gorris LGM. Food safety objective: an integral part of food chain management. Food Control 2005; 16: 801-809.

5 World Health Organization. WHO Global strategy for Food Safety. Safer Food for Better Health. Geneva, World Health Organization, 2002. www.who.int/foodsafety/ publications/general/en/strategy_en.pdf. Date last accessed: February 4, 2008.

6 Jaakkola MS, Nordman H, Piipari R, et al. Indoor dampness and molds and development of adult-onset asthma: a population-based incident case-control study. Environ Health Perspect 2002; 110: 543-547.

7 Jaakkola JJK, Jaakkola N, Piipari R, Jaakkola MS. Pets, parental atopy, and asthma in adults. J Allergy Clin Immunol 2002; 109: 784-788.

8 Jaakkola MS, Piipari R, Jaakkola N, Jaakkola JJK. Environmental tobacco smoke and adult-onset asthma: a population-based incident case-control study. Am J Public Health 2003; 93: 2055-2060.

9 Jaakkola JJK, Piipari R, Jaakkola MS. Occupation and asthma: a population-based incident case-control study. Am J Epidemiol 2003; 158: 981-987.

10 Piipari R, Jaakkola JJK, Jaakkola N, Jaakkola MS. Smoking and asthma in adults. Eur Respir J 2004; 24: 734-739.

11 Jaakkola MS, Ieromnimon A, Jaakkola JJK. Are atopy and specific IgE to mites and molds important for adult asthma? J Allergy Clin Immunol 2006; 117: 642-648.

12 Jaakkola JJK, Ieromnimon A, Jaakkola MS. Interior surface materials and asthma in adults: a population-based incident case-control study. Am J Epidemiol 2006; 164: 742-749.

13 Jaakkola MS, Jaakkola JJK. Office work exposures and adultonset asthma. Environ Health Perspect 2007; 115: 1007-1011.

14 Standardization of spirometry, 1994 update. American Thoracic Society. Am J Respir Crit Care Med 1995; 152: 1107-1136.

15 Dejsomritrutai W, Maranetra N, Maneechotesuwan K, et al. Reference spirometric values for healthy lifetime nonsmokers in Thailand. J Med Assoc Thai 2000; 83: 457-466.

16 Eller PM, Cassinelli ME. NIOSH Manual of Analytical Methods. 4th Edn. Department of Health and Human Services (National Institute for Occupational Safety and Health), Publication No. 94-113. Ohio, Centers for Disease Control and Prevention, 1994.

17 Burge PS. How to take an occupational exposure history relevant to lung disease. In: Hendrick DJ, Burge PS, Beckett 
WS, Churg A, eds. Occupational Disorders of the Lung: Recognition, Management and Prevention. London, WB Saunders, 2002; pp. 26-29.

18 Liss GM, Tarlo SM. Natural rubber latex related occupational asthma: association with interventions and glove changes overtime. Am J Ind Med 2001; 40: 347-353.

19 Saary MJ, Kanani A, Alghadeer H, Holness DL, Tarlo SM. Changes in rates of natural rubber latex sensitivity among dental school students and staff members after changes in latex gloves. J Allergy Clin Immunol 2002; 109: 131-135.

20 Allmers H, Schmengler J, Skudlik C. Primary prevention of natural rubber latex allergy in the German healthcare system through education and intervention. J Allergy Clin Immunol 2002; 110: 318-323.

21 LaMontagne AD, Radi S, Elder DS, Abramson MJ, Sim M. Primary prevention of latex-related sensitisation and occupational asthma: a systemic review. Occup Environ Med 2006; 63: 359-364.

22 James JM, Crespo JF. Allergic reactions to foods by inhalation. Curr Allergy Asthma Rep 2007; 7: 167-174.

23 Bernaola G, Echechipia S, Urrutia I, Fernandez E, Audicana M, Fernandez de Corres L. Occupational asthma and rhinoconjunctivitis from inhalation of dried cow's milk caused by sensitization to $\alpha$-lactalbumin. Allergy 1994 ; 49: 189-191.

24 Toskala E, Piipari R, Aalto-Korte K, Tuppurainen M, Kuuliala O, Keskinen H. Occupational asthma and rhinitis caused by milk proteins. J Occup Environ Med 2004; 46: 1100-1101.

25 Olaguibel JM, Hernandez D, Morales P, Peris A, Basomba A. Occupational asthma caused by inhalation of casein. Allergy 1990; 45: 306-308.

26 Rossi GL, Corsico A, Moscato G. Occupational asthma caused by milk proteins: report on a case. J Allergy Clin Immunol 1994; 93: 799-801.

27 Bousquet J, Flahault A, Vandenplas O, et al. Natural rubber latex allergy among healthcare workers: a systemic review of the evidence. J Allergy Clin Immunol 2006; 118: 447-454.

28 Alanko K, Susitaival P, Jolanki R, Kanerva L. Occupational skin diseases among dental nurses. Contact Dermatitis 2004; 50: 77-82.

29 Hammann CP, Rodgers PA, Sullivan KM. Occupational allergens in dentistry. Curr Opin Allergy Clin Immunol 2004; 4: 403-409. 